\title{
NEUROIDENTIFICATION WITH Neuro-Self Tuning TO ENSURE THE OPERATION OF THE CURRENT LOOP OF THE ELECTRIC DRIVE WITH THE DESIRED STATIC AND DYNAMIC CHARACTERISTICS
}

\section{НЕЙРОИДЕНТИФИКАЦИЯ С НЕЙРОСАМОНАСТРОЙКОЙ ДЛЯ ОБЕСПЕЧЕНИЯ \\ РАБОТЫ ТОКОВОГО КОНТУРА ЭЛЕКТРОПРИВОДА С ЖЕЛАЕМЫМИ СТАТИЧЕСКИМИ И ДИНАМИЧЕСКИМИ ХАРАКТЕРИСТИКАМИ}

\author{
BUYANKIN, Viktor M. ${ }^{1}$ \\ 1Bauman Moscow State Technical University 105005, 5 Second Baumanskaya Street, Moscow - \\ Russian Federation \\ Corresponding author \\ e-mail: viktor-buyankin@yandex.ru
}

Received 21 March 2018; received in revised form 01 May 2018; accepted 10 May 2018

\section{RESUMO}

A síntese de reguladores neurais para sistemas de controle de acionamentos elétricos é considerada no artigo. O trabalho estável e as características da aplicação de reguladores neurais em circuitos fechados são analisados. Neuro-reguladores se auto-ajustam ao mudar os parâmetros do objeto de controle. As informações sobre a mudança nos parâmetros do objeto de controle são comparadas com as características ótimas desejadas do modelo de referência e os sinais de treinamento são gerados para os neuroreguladores, que fornecem as características estáticas e dinâmicas ótimas necessárias do acionamento elétrico.

Palavras-chave: neurorregulador, síntese, materiais, treinamento, inteligência artificial.

\section{ABSTRACT}

The synthesis of neural regulators for control systems of electric drives is considered in the article. The stable work and features of the application of neural regulators in closed circuits are analyzed. Neuroregulators self-adjust when changing the parameters of the control object. Information on the change in the parameters of the control object is compared with the optimal desired characteristics of the reference model, training signals are generated for the neuroregulators, which provide the necessary optimal static and dynamic characteristics of electric drive.

Keywords: neuroregulator, synthesis, materials, training, artificial intelligence.

\section{АННОТАЦИЯ}

В статье рассматривается синтез нейрорегуляторов для систем управления электроприводами. Проанализирована стабильная работа и особенности применения нейрорегуляторов в замкнутых цепях. Нейрорегуляторы самонастраиваются при изменении параметров объекта управления. Информация об изменении параметров объекта управления сравнивается с оптимальными желаемыми характеристиками эталонной модели, генерируются сигналы обучения для нейрорегуляторов, которые обеспечивают необходимые оптимальные статические и динамические характеристики привода.

Ключевые слова:нейрорегулятор, синтез, материалы, обучение, искусственный интеллект. 


\section{INTRODUCTION}

The architecture of the neural network plays an important role in the effectiveness of training. The dimension of the input and output layers of the neural network is determined from the conditions of the problem or training sample.

As it was proved in (Uglov et al., 2007), with the help of a three-layer neural network it is possible to approximate any function with arbitrarily given accuracy. The accuracy of the approximation depends on the number of neurons in the hidden layer. The greater the number of neural elements in the hidden layer, the greater the accuracy.

Control of the technical condition of the product in the process of diagnosis is carried out with the help of neural predictors (Uglov et al., 2007). A neural predictor is a mathematical model based on an artificial neural network that predicts the output state vector of a product by its prehistory one step forward (Wang and Hong, 2000). To use the neural predictor, it must be trained on the data obtained during the diagnosis of a serviceable product when it operates in various dynamic modes. In training, the neural network approximates the functional dependence between the input signals $X$ and the output signals $Y(C h o, 2016)$.

As an example (Masalimov and Munasypov, 2017), for the input signals, the voltages on the windings, the angular velocity and the resistance moment received in the ins from the sensors, and additionally the same signals delayed for some time, act (Gholamiand Sotskov, 2014). The output signal is the predicted one-step electric current in the winding (Buyankin and Rusakov, 2004).

After training, the neural predictor connects to the object of diagnosis. The prediction accuracy of the predictor depends on the training time, the amount and quality of training samples (Buyankin and Rusakov, 2004).

When the correct object of diagnosis (motor) output signal predictor almost coincides with the actual measured current, and in the event of a fault occurs mismatch $\Delta$ (Kondrat'ev and Tyumentsev, 2013). The size and sign of misalignment, as well as the rate of change in the value of misalignment, can diagnose the technical condition of the product (Fessant et al., 1996).

Forecasting of the state of $O D$ is carried out on the same principle as the formation of a training sample (Wang and Hong, 2000; Pu and Xu, 2001; Liao et al., 2008; Wu and Feng, 2017; Yamada, 2010). There are two possibilities: onestep and multi-step forecasting (Yousif et al, 2015). One-step forecasting is used for shortterm forecasts. This forecast is carried out only for the required time interval (mileage), for this purpose the real technical condition of $O D$ is used (taken into account), not the predicted value, for the realization of the forecast at the next step (Kondo C. and Kondo T., 2009; Fessant et al., 1996; Lee, 2001; Sen-linand Meiqin, 2005; El Shazly M. R. and El Shazly H., 1999).

\section{MATERIALS AND METHODS}

Multistage forecasting is used to implement long-term forecasting and is intended to determine the basic pattern of changes in the technical condition of the product, for a certain period of time in the future. Thus the forecasting system uses the received (output) data for the established time intervals (runs). Suppose the system has learned to recognize the technical condition of the product at a certain time interval (mileage). The system then predicted the technical condition of the product (OD) at the next time interval of interest to the researcher, when the last of the known images were submitted to its input. After that, the system makes further forecasting and the next image received by the system is submitted to the input. The last element of this image in the specified work interval (mileage) of the item is the forecast of the system.

The proposed method of predicting the technical condition of the product on the basis of the mathematical apparatus of artificial neural networks allows obtaining performance by parallelizing the flows of processing diagnostic information and improving the reliability of the forecast. 
RESULTS AND DISCUSSIONS:

Let us consider a single-circuit electric motor current circuit control system which is presented in Fig. 1.

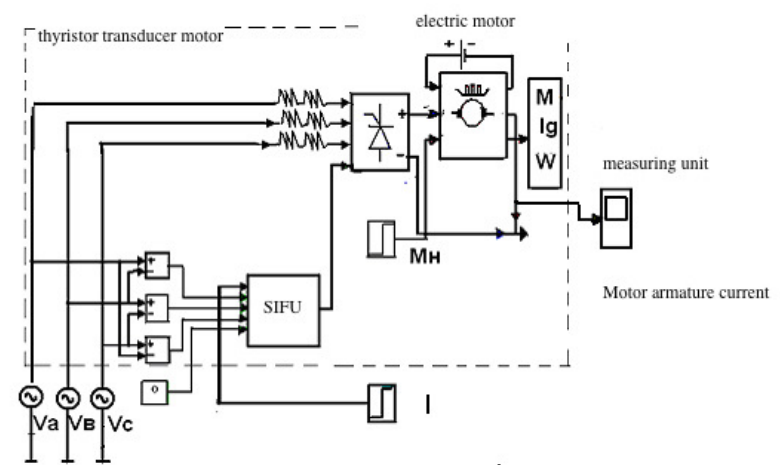

Figure 1.A functional diagram of electric motor current circuit control in MATLAB environment

The real work of the electric drive shown in Fig. 1 can only be described approximately by a system of linear and nonlinear equations (Buyankin and Rusakov, 2004):

The equation of the field winding (Eq. 1):

$u_{B}=L_{B} \frac{d i_{B}}{d t}+r_{B} i_{B}$

The equation of the field winding (Eq. 2):

$u_{Я}=L_{Я} \frac{d i_{Я}}{d t}+r_{Я} i_{Я}+e_{Я}$

The equation of moments on the motor shaft (Eq. 3):

$J \frac{d \omega_{m}}{d t}=M-M_{H}$

The equation for thyristor Converter (Eq. 4):

$\Phi_{B}=k_{\Phi} i_{B}$,

$e_{\text {Я }}=k_{g} \omega_{m} \Phi_{B}$,

$M=k_{M} i_{Я} \Phi_{B}$.

$U_{Z}=U_{m}(1+\cos (\alpha)) / 3.14$

(Eq. 4) where,

$U_{B}$ voltage in the excitation winding,

$i_{B}$ excitation current,

$r_{B}$ active resistance of the field winding,

$L_{B}$ coil inductance,

$\Phi_{B}$ the magnetic flux of the field winding,

$U_{Я}$ armature voltage,

$i_{Я}$ armature current,

$e_{Я}$ are EMF anchors

$r_{Я}$ the resistance of the armature,

$L_{Я}$ the inductance of the armature,

$J$ moment of inertia,

$W$ frequency of motor rotation,

$M$ motor torque,

$M_{H}$ load torque,

$k_{g}$ the ratio of the EMF of the motor,

$k_{m}$ moment coefficient of the motor,

$U_{m}$ the amplitude of the voltage,

$\alpha$ the angle of firing of the thyristors.

The transient can determine the parameters of the current circuit and obtain a differential expression of the output current signal of the motor (Eq. 5).

$I_{\boldsymbol{A}_{k}}=F_{0}\left[U_{k}+U_{k-1}+U_{k-2}+\ldots \ldots \ldots+U_{k-n}\right]$ (Eq. 5)

Developed a neural network to the identification operation current loop of the motor and provide training of the neural network 
scheme depicted in Fig. 2. The neural network has four neurons in the input layer and one neuron in the output.

Equations SP neuroregulator have the following form:

$Y N_{1}=Y N_{0} * Z^{-1}-$ The output signal of the neural network, delayed for one clock cycle (Eq. $6)$ :

$$
\left.\begin{array}{l}
y_{1}=X N_{0} * w_{11}+Y N_{1} * w_{12}+b_{11} \\
y_{2}=X N_{0} * w_{21}+Y N_{1} * w_{22}+b_{12} \\
y_{3}=X N_{0} * w_{31}+Y N_{1} * w_{32}+b_{13} \\
y_{4}=X N_{0} * w_{41}+Y N_{1} * w_{42}+b_{14} \\
y_{11}=\operatorname{purelin}\left(y_{1}\right) \\
y_{12}=\operatorname{purelin}\left(y_{2}\right) \\
y_{13}=\operatorname{purelin}\left(y_{3}\right) \\
y_{14}=\operatorname{purelin}\left(y_{4}\right)
\end{array}\right\}
$$

Equations of the first neuron input layer (Eq. 7):

$$
y_{222}=W_{21} * y_{11}+W_{22} * y_{12}+W_{23} * y_{13}+W_{24} * y_{14}+B_{21}(\text { Eq. } 7)
$$

Equations of the second output layer of neurons (Eq. 8):

$$
Y N_{0}=\operatorname{purelin}\left(y_{222}\right) \text {. }
$$

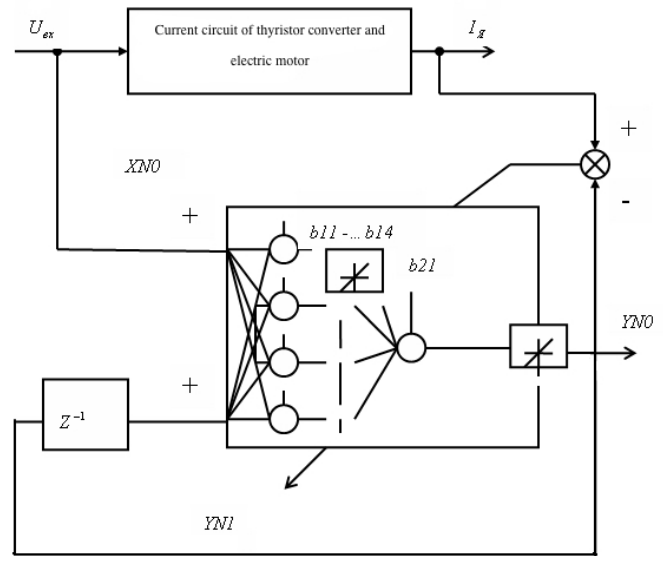

Figure 2. Training Scheme of the neural network

As a result, after training, the transition process of the neural network with the required specified accuracy repeats the transition process of the nonlinear system of the thyristor
Converter and motor, that is, completely copes with the task of identification.

We will neurosemantics current loop of the drive. The block diagram of the circuit neuro-selft uning unit with near identical shown in Fig. 3.

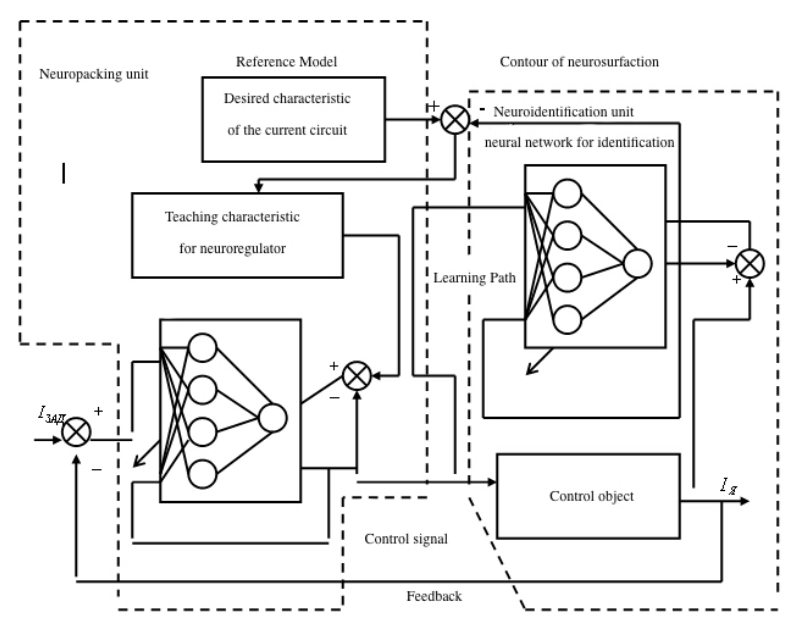

Figure 3. Block diagram of neuro-self tuning circuit

Contour neuro-self tuning consists of the reference model with the desired characteristics of the current loop. The desired output signal is described by the following difference equation (Eq. 9):

$I_{g g_{k}}=F g\left[I z_{k}+I z g_{k-1}+I z g_{k-2}+\ldots \ldots . .+I z g_{k-n}\right]($ Eq. 9)

Data block near identical data is compared with the reference model, by comparing obtained signals learning to neuro regulator.

Neuro-regulator has an integrally proportional structure to perform the role of compensation of electromagnetic time of the motor, which significantly improves the static and dynamic characteristics of the current circuit.

Equations SP neuroregulator have the following form:

The signal at the input of the neural network (Eq. 10):

$$
I Z=X N 0
$$


The signal at the entrance of the neural network, delayed by one stroke (Eq. 11):

$$
X N 1 t k=X N 0 t k * Z^{-1}
$$

The signal at the output of the neural network, delayed for one clock cycle (Eq. 12):

$$
Y N 1 t k=Y N 0 t k * Z^{-1}
$$

Equations of the first input layer (Eq. 13):

$$
\left.\begin{array}{l}
y_{1}=X N 0 t k * w_{11}-X N 1 t k * w_{12}+Y N 1 t k * w_{13}+b_{11} \\
y_{2}=X N 0 t k * w_{21}-X N 1 t k * w_{22}+Y N 1 t k * w_{23}+b_{12} \\
y_{3}=X N 0 t k * w_{31}-X N 1 t k * w_{32}+Y N 1 t k * w_{33}+b_{13} \\
y_{4}=X N 0 t k * w_{41}-X N 1 t k * w_{42}+Y N 1 t k * w_{43}+b_{14} \\
y_{11}=\operatorname{purelin}\left(y_{1}\right) \\
y_{12}=\operatorname{purelin}\left(y_{2}\right) \\
y_{13}=\operatorname{purelin}\left(y_{3}\right) \\
y_{14}=\operatorname{purelin}\left(y_{4}\right)
\end{array}\right\}
$$

Equations of the second output layer (Eq. 14):

$$
\left.\begin{array}{l}
y_{222}=W_{21} * y_{11}+W_{22} * y_{12}+W_{23} * y_{13}+W_{24} * y_{14}+B_{21} \\
\left.Y N 0 t k=\text { purelirk } y_{222}\right)
\end{array}\right\}
$$

The work of the neuroregulator is described by a difference expression (Eq. 15):

$$
U_{k}=U\left[E_{k}+E_{k-1}+E_{k-2}+\ldots . .+E_{k-n}\right] \text { (Eq. 15) }
$$

where

$$
\begin{aligned}
& E(k)=I_{Z}(k)-I_{Я}(k) \\
& E(k-1)=I_{Z}(k-1)-I_{Я}(k-1) \\
& E(k-2)=I_{Z}(k-2)-I_{Я}(k-2) \\
& \cdots \cdots \cdots \cdots \cdots \cdots \cdots \cdots \cdots \cdots \cdots \cdots \cdots \cdots \cdots \cdots \cdots \cdots \cdots \cdots \cdots \cdots \cdots \cdots \cdots \cdots \cdots \cdots \cdots \cdots \cdots \\
& E(k-n)=I_{Z}(k-n)-I_{\text {Я }}(k-n)
\end{aligned}
$$

The different parameters of the motor (different inductors) were obtained by the family educational characteristics of neuroregulator.

As a result of neuroregulator training, the current circuit with neuro-self tuning has a transient process coinciding with the desired transient process of the reference model. When changing the parameters of a nonlinear system of thyristor Converter and the motor unit near identical keeps track of these changes when comparing with the parameters of the reference model creating a new training feature for neuroregulator and at the end of the transition process current loop remains as before without any changes coincident with the desired Fig.4.

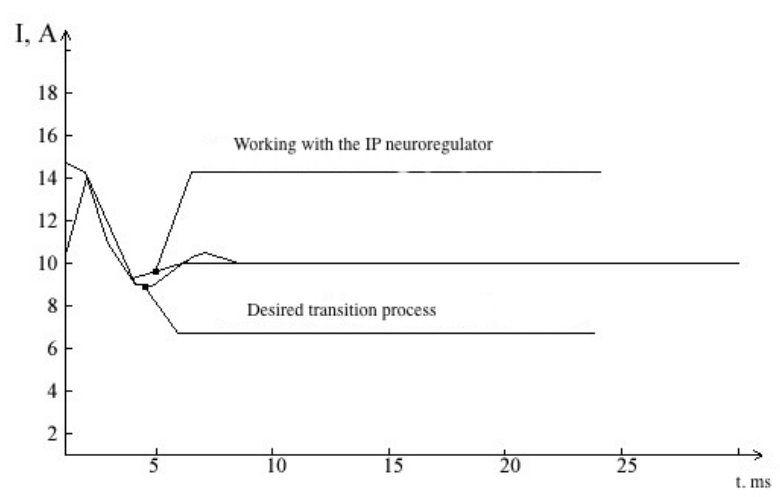

Figure 4. The transients of the armature current of the electric motor in a current loop

Thus, the control system with neuroidentification with neuro-self tuning and neuroregulator provides the current circuit with the desired static and dynamic characteristics despite changes in the parameters of the motor.

\section{CONCLUSIONS:}

Traditional control methods based on classical concepts of automatic control theory for linear systems have achieved sufficient perfection so far. In principle, using, for example, modal control methods or subordinate control systems, it is possible to synthesize systems that provide a high quality of both static and dynamic control indicators of electric drive coordinates. In the analytical synthesis of parameters of such systems are widely used matrix, root, topological methods, which have received significant development in recent years.

However, this control requires the introduction of external feedbacks for most of the coordinates of the actuator. This not only complicates the system but also makes it difficult to implement it when it is necessary to have information about hard-to-measure coordinates, such as, for example, the elastic moment in a certain kinematic connection. The use of 
observers to measure such coordinates significantly complicates the electromechanical system. Another disadvantage of such systems may be the inability to implement the synthesized control laws for various reasons.

Obviously, to eliminate the above shortcomings could be the introduction into the system of a non-linear regulator, which had at the entrance information on the easily measured one or more coordinates and would provide the required control of the electric drive. Such regulators may include neuro-controllerstechnical devices built on the basis of artificial neural networks of different organizations, which can be implemented using different hardware or firmware.

As shown by earlier studies, for the realization of closed control systems with a neural network to control a DC motor sequential excitation is enough one feedback on motor speed, with the discretization of a pure delay unit. In these works, the mechanical part of the electric drive was represented by a one-mass design scheme. However, in the real drive system kinematic constraints are not perfectly rigid and therefore the performance of an electromechanical system as a single-mass can lead to significant errors. Elastic elements can cause resonance modes, the appearance of large dynamic overloads in the elements of the electric drive, the development of fatigue phenomena and failures. If the synthesis of the system does not take into account the elastic kinematic connection, it can lead to differences in the nature of the movement of the Executive body and the motor shaft from the design, that is, to a violation of the specified operating mode of the mechanism. Thus there is a problem of synthesis of neural network control system of the two-mass electromechanical system with a sequential excitation motor.

\section{REFERENCES:}

1. Buyankin V. M.; Rusakov V. M.; Influence of external disturbing influences on the accuracy of the microprocessor electric drive. Bulletin of Bauman MGTU. 2004, 2, 54.

2. Buyankin V. M.; Rusakov V. M.; Research of static and dynamic accuracy of microprocessor electric drive. Bulletin of Bauman MGTU. 2004, 2, 52.
3. Cho M. W.; Neural network regulation driven by autonomous neural firings. I Korean Phys Soc. 2016, 69, 107-112.

4. El Shazly M. R.; El Shazly H.; Forecasting currency prices using a genetically evolved neural network architecture. Int Adv Econ Res. 1999, 5, 148.

5. Fessant F.; Bengio S.; Collobert D.; On the prediction of solar activity using different neural network models. Ann Geophys.1996, 14, 20-26.

6. Gholami O.; Sotskov Y. N.; Erratum to: "A neural network algorithm for servicing jobs with sequential and parallel machines". Autom Remote Control. 2014, 75, 1716.

7. Kondo C.; Kondo T.; Revised GMDH-type neural network algorithm self-selecting optimum neural network architecture. Artif Life Robot. 2009, 14, 519-523.

8. Kondrat'ev A. I.; Tyumentsev Y. V.; Application of neural networks for the design of flight control algorithms. II Adaptive tuning of neural network control law. Russ Aeronaut (Iz VUZ). 2013, 56, 257-265.

9. Kondrat'ev A. I.; Tyumentsev Y. V.; Application of neural networks for synthesizing flight control algorithms. I neural network inverse dynamics method for aircraft flight control. Russ Aeronaut (Iz VUZ). 2013, 56, 135-144.

10. Lee H. K. H.; Model Selection for Neural Network Classification. J Classif. 2001, 18, 227-243.

11. Liao X.; Zhang Y.; Yang S.; Lin C.; Research on fault location technology based on BP neural network in DWDM optical network. Optoelectron Lett. 2008, 4, 452455.

12. Masalimov K. A.; Munasypov R. A.; Neuralnetwork diagnostics of electrochemical machining. Russ Eng Res. 2017, 37, 817820.

13. Pu Z.; Xu D.; Global Attractivity and Global Exponential Stability for Delayed Hopfield Neural Network Models. Appl Math Mech. 2001, 22, 711-716. 
14. Sen-lin Z.; Mei-qin L.; Stability analysis of discrete-time BAM neural networks based on standard neural network models. $J$ Zhejiang Univ A. 2005, 6, 689-696.

15. Uglov J.; Jakaite L.; Schetinin V.; Maple C.; Comparing Robustness of Pairwise and Multiclass Neural-Network Systems for Face Recognition. EURASIP J Adv Signal Process (2007), doi:10.1155/2008/468693.

16. Wang B.-Z.; Hong J.; Artificial Neural Network Models for the Gap Discontinuities in Stripline Circuits. Int $J$ Infrared Millimeter Waves. 2000, 21, 677-688.
17. Wu Y.; Feng J.; Development and Application of Artificial Neural Network. WirelPersCommun(2017),

doi:10.1007/s11277-017-5224-x.

18. Yamada T.; Transformation of neural network weight trajectories on a 2D plane for a learning-type neural network direct controller. Artif Life Robot. 2010, 15, 413416.

19. Yousif N.; Mace M.; Pavese N.; Borisyuk R.; Nandi D.; Bain P.; A network model of neural activity in essential tremor. $B M C$ Neurosci

doi:10.1371/journal.pcbi.1005326. 